\title{
Student perceptions towards the usage of AR-supported STEMUP application in mobile courses development and its implementation into English learning
}

\author{
Huang-Yao Lin \\ Department of Cultural and Creative Industries, National Kaohsiung University of Science and \\ Technology, Kaohsiung, Taiwan \\ Shu-Chiao Tsai \\ Center of Liberal Arts, National Kaohsiung University of Science and Technology, Kaohsiung, Taiwan
}

\begin{abstract}
This study investigated the use of an augmented reality (AR) -supported application called STEMUP to develop mobile English courses on Android and iOS smartphones. It focused on vocabulary and listening and speaking skills, in an initial assessment of the effectiveness of implementing AR-based mobile English courses. The study was conducted with English major sophomores who took an elective course, Design and Practice of Mobile Learning, at a technology university in Taiwan. A preliminary curriculum was prepared for integrating STEMUP into English courses in which students would not only learn how to develop ARbased mobile English courses but also practise target English skills with two assigned English courses on STEMUP. The results from the student questionnaire indicated that the layout design of the student-generated AR-based mobile English courses complied with several of Mayer's principles of multimedia learning and that the focus on learning with the mobile English courses met Chapelle's seven suggested criteria for the development of multimedia computer-assisted language learning. The students of English as a foreign language responded that STEMUP was an easy application for developing AR-based mobile English courses and that learning with the assigned AR-based mobile English courses was interesting and motivational.
\end{abstract}

\section{Implications for practice or policy:}

- Teachers of English as a foreign language can easily develop AR-based mobile English courses on STEMUP by referring to Mayer's principles of multimedia learning.

- Focusing on learning English language with AR-based mobile courses meets Chapelle's suggested criteria for development of multimedia computer-assisted language learning.

- This AR-supported STEMUP can be extended to educational settings, especially in remote schools that lack English learning resources and teachers.

Keywords: augmented reality (AR), English as a foreign language (EFL), English learning, mobile learning, student perceptions, app development

\section{Introduction}

English skills in listening, speaking, reading and writing play an important role in the success of many international career fields such as academe, business, finance, technology and international relations. Thus, how to effectively improve English skills for fluent communication is an important issue, especially in many non-English-speaking countries. Various methods and pedagogical approaches in the field of English language teaching and learning have been introduced to improve the English skills of students of English as a foreign language (EFL). Among these skills, listening and speaking are less emphasised in the EFL classroom, compared with reading and writing skills, particularly in countries of the Asia-Pacific region (Cheon, 2003; Liu, 2009; Tsou, 2005).

Some difficulties have been encountered in promoting listening and speaking skills in EFL students (Hwang et al., 2014; Liu, 2009). First, there are few or limited opportunities for EFL students to practise speaking and listening skills with their English teachers and classmates, not to mention with native English speakers. Second, there is a lack of appropriate learning materials or environments connected with real life to stimulate their learning motivation and interest. Third, students seldom receive the needed instantaneous, sufficient and effective feedback for modifying their linguistic output. In addition, some students are 
generally shy and feel anxious about answering questions in English in class, probably due to locally influenced pedagogy or their fear of making errors (Hwang et al., 2014; Lu et al., 2019). Thus, how to develop an effective environment that provides interactive activities for English learning is an important issue in the field of computer-assisted language learning (CALL).

With the rapid development of mobile technology, augmented reality (AR) is one of the innovative technologies for enhancing interaction between real and virtual space by superimposing virtual objects or information on the physical environment. Smartphones and tablets with AR technology have increasingly been used as a pedagogical tool in several educational fields, including science (Moreno et al., 2020; Sahin \& Yilmaz, 2020), engineering (Delgado et al., 2020; Radosavljevic et al., 2020), health (Celik et al., 2020; Tang et al., 2020) and language (Hwang et al., 2016; Y. C. Liu \& Hsieh, 2018). AR can contribute to education with several advantages in the learning process, such as stimulating motivation (Bacca et al., 2019; J. Zhang et al., 2014), increasing interest and curiosity (Cabero \& Roig, 2019), enhancing engagement and involvement (Yilmaz et al., 2017), facilitating content comprehension (Habig, 2019), promoting learning effectiveness (Fidan \& Tuncel, 2019) and helping to create an autonomous and contextaware learning environment (de Almeida Mello \& Cabero Almenara, 2020; Huang \& Chiu, 2014).

In terms of language learning, mobile assisted language learning (MALL) combined with AR technology, an emerging area in CALL, has a number of advantages, such as promoting learner's motivation, attention and satisfaction (Hsu, 2017; W.-Y. Hwang et al., 2014; Küçük et al., 2014); providing a ubiquitous and interactive learning environment (W.-Y. Hwang et al., 2014; Santos et al., 2106); increasing opportunities to access learning activities and engage in learning tasks (Hsu, 2017; Santos et al., 2106); enabling a more flexible and equal participation in the learning process (Küçük et al., 2014; Safar et al., 2017; Solak \& Cakir, 2015); and offering collaborative learning (W.-Y. Hwang et al., 2014). Ibrahim (2019) has recently identified the benefits of mobile learning in English language from the perceptions of learners and teachers and suggested that mobile technology should be considered by curriculum designers and materials developers.

\section{Literature review}

\section{AR-based mobile English learning}

AR integrates real fields and virtual images to provide users with an interactive experience in real time, which can improve learning interest, motivation and effectiveness (Fidan \& Tuncel, 2019; Ibrahim et al., 2017; Radosavljevic et al., 2018; Sahin \& Yilmaz, 2020). In addition, mobile AR refers to the mobility of the small and portable device for producing AR, which has made its adoption much easier and convenient and provided new ways to promote English education. In an exploratory case study using AR-based mobile EFL learning material with five undergraduate students majoring in English, P.-H. E. Liu and Tsai (2013) found that the students engaged in the learning scenario, acquired linguistic and content knowledge and produced meaningful essays. In a study with 122 fifth-grade students from five secondary schools, Küçük et al. (2014) found that the students were satisfied with learning English by using AR applications; they had a low anxiety level and low levels of cognitive load during the learning process in the AR environment. W. Y. Hwang et al. (2016) created a mobile game-based learning environment with situational contexts to facilitate students' English listening and speaking skills and found that their speaking skills were more significantly improved than their listening skills. Y. C. Liu and Hsieh (2018) found that fifth-grade students performed significantly better in an English vocabulary test after using AR teaching materials. Hao and Lee (2019) developed four AR games and investigated their influence on the learning of 147 fifth-grade students; they found that, compared with those who underwent traditional learning, the students who received AR game learning exhibited significantly higher learning motivation. Furthermore, Hao and Lee concluded that 3D graphics are the most important element in AR game designs.

Although AR is being increasingly used for English education, there is a lack of design-based studies on the development of AR-based learning materials and their implementation into English instruction (Safar et al., 2017; S. Zhang, 2018). Developing AR-based mobile English learning materials and their implementation in EFL instruction is a tough task that requires collaboration with programmers, apps designers, subject experts, curriculum developers, educators, evaluators and language teachers (Nami, 2020). Some problems have been found in using AR in language education. For example, learners are often 
unfamiliar with AR-based mobile learning material and the use of the device and they lack adequate scaffolding or guidelines (P.-H. E. Liu \& Tsai, 2013; Y. Liu et al., 2016; Perry, 2015; S. Zhang, 2018).

In the face of continuous innovation in information and communications technology, EFL teachers with sufficient teaching knowledge and methodology usually lack the information literacy and ability to develop AR-based teaching materials on their own. Therefore, creating a simple and user-friendly platform for producing AR-based courses will not only help EFL teachers easily develop interactive teaching materials according to learner needs and the design of the curriculum but also greatly expand the application and effectiveness of AR technology in English education.

\section{STEMUP application}

In 2019, a technical team at the Institute of Information Industry developed an AR-supported application called STEMUP. This study aimed at investigating whether EFL users (who generally have less computerrelated knowledge and lack ability in programming) could easily develop AR-based mobile English learning materials or courses on STEMUP. In addition, it was interesting and important to investigate what benefits or challenges could be brought for EFL learners while learning with AR-based mobile learning materials or courses developed by using STEMUP.

STEMUP is a marker-based AR application programmed in the cross-platform Unity engine and used on both Android and iOS-based smartphones for developing AR-based mobile English courses, focusing mainly on learning vocabulary and developing listening and speaking skills. It can add free online 3D objects to create AR-supported learning content. The usage of STEMUP is briefly explained as follows: After deciding the course theme, the course designer starts planning a set of question and answer (Q\&A) dialogues. According to the order of the planned dialogues, each dialogue will be given a distinctive number of images provided by STEMUP in the editing process, and then the course designer can choose an appropriate 3D object for each dialogue from a free database connected to the Internet. STEMUP also connects to the online services of Google text-to-speech and speech recognition so that learners to can practise and correct their English listening and speaking skills. During the learning process, when learners point at a number image on the poster of the target theme by using the cameras of their mobile phones and the number image is recognised, the corresponding Q\&A dialogue and the AR of its 3D object appears on the screen of the smartphone, as shown and explained in Figure 1. The course designer can place these number images at any suitable location on the theme background.

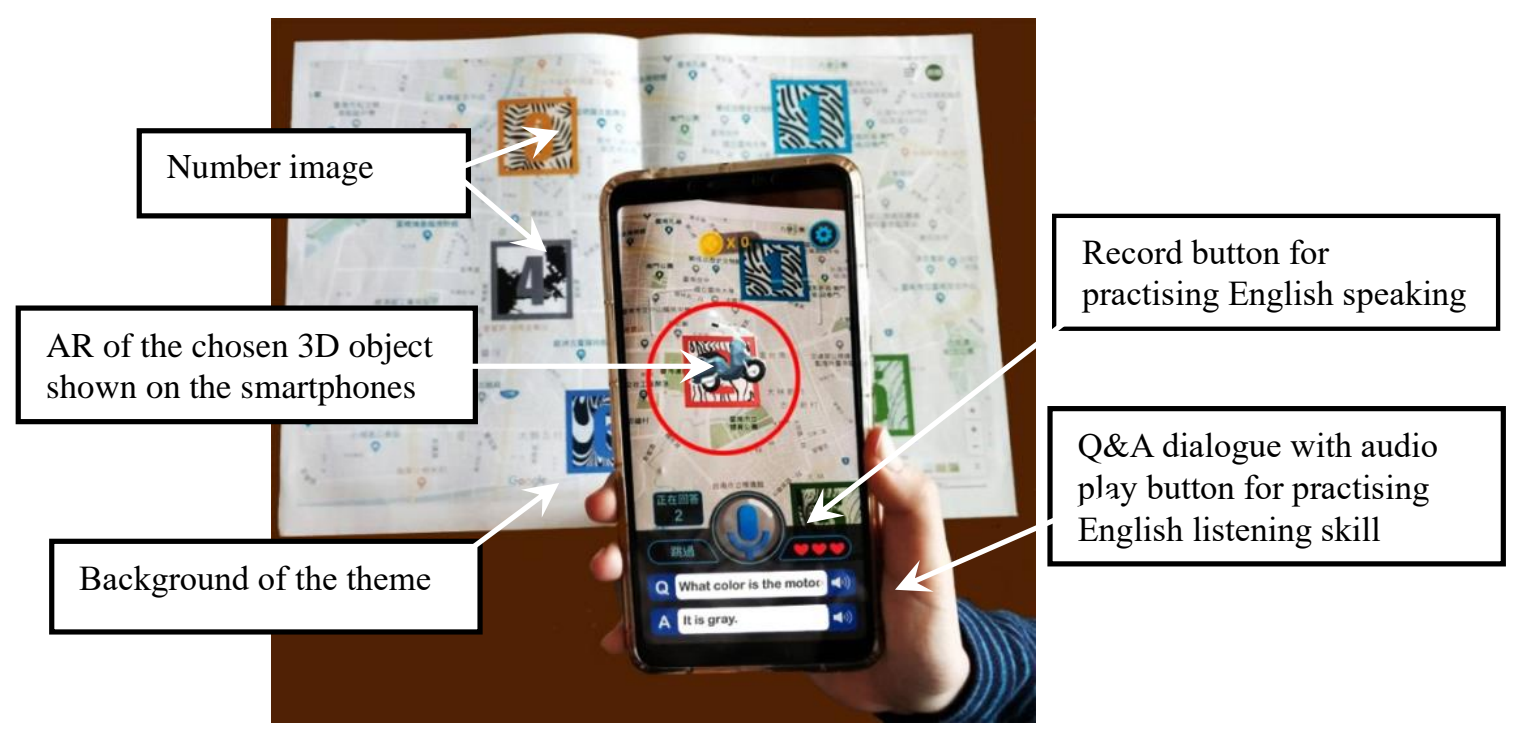

Figure 1. Corresponding Q\&A dialogue and its AR of the 3D object shown on the screen of the smartphone when the dialogue number image is identified as recognised 
Due to the limited screen size of smartphones, the layout of STEMUP is as simple and easy to operate as possible. After logging in, users access the main page consisting of four sections on the top of the screenshot shown in Figure 2: "Start" for linking to the list of all the AR-based courses; "Room" for creating a classroom for a specific course so that students can directly access the learning content of the AR-based course; "Create" for developing a new AR-based course; "Record" for checking the learning portfolio of students in an assigned course.

After clicking on the blue icon of "Create", two icons are presented in the centre of the screen, as shown in Figure 2: "Course Creation" for developing new AR-based courses and "Course Management" for checking learning content of uploaded AR-based courses, AR-based courses in progress and a database of the chosen 3D objects from the Internet. By further clicking on "Course Creation", users can access a new page as shown (Figure 3) to edit the course title and its description in Chinese or English. Then, the user has access to the following page (Figure 4) to edit the dialogue content according to the order of each dialogue and choose an appropriate 3D object for each dialogue from a free database on the Internet, as shown in Figure 4. When a 3D object is chosen, its presentation orientation and size can further be adjusted. After editing the learning content, users have to store the file and upload it to the STEMUP platform system for downloading by learners. In addition, a poster of the target theme can be prepared, on which the number images can be appropriately placed for learners to conduct the recognition of number images and start learning, as shown in Figure 1.

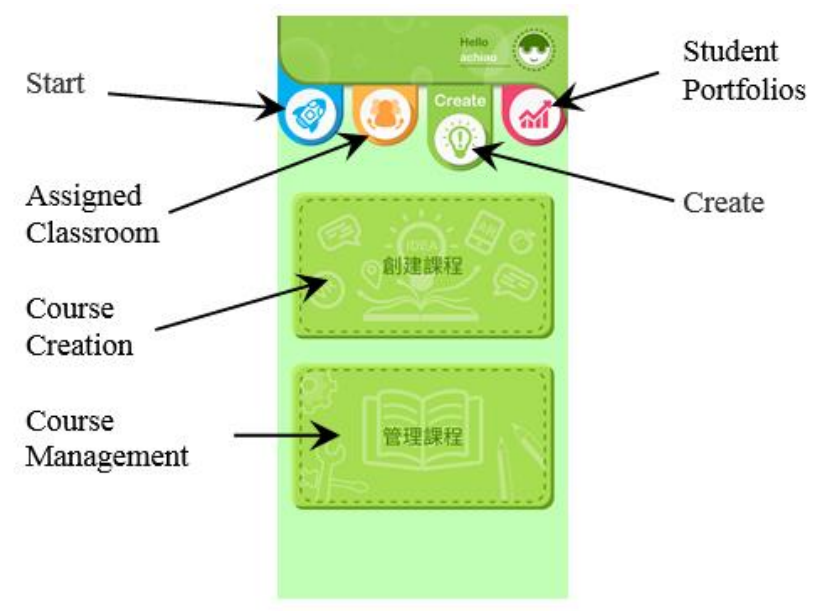

Figure 2. Screenshot of course creation

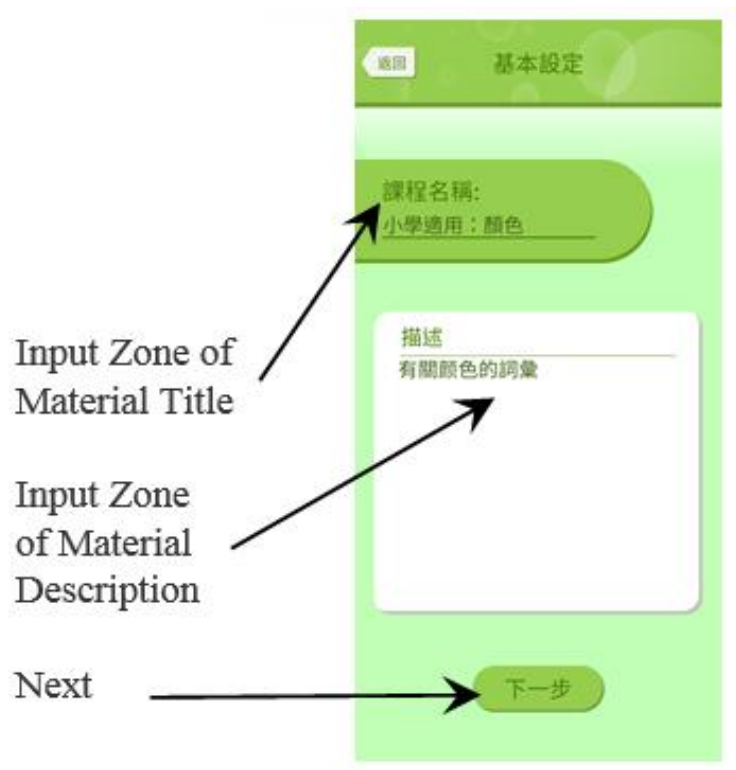

Figure 3. Input zones of course creation 


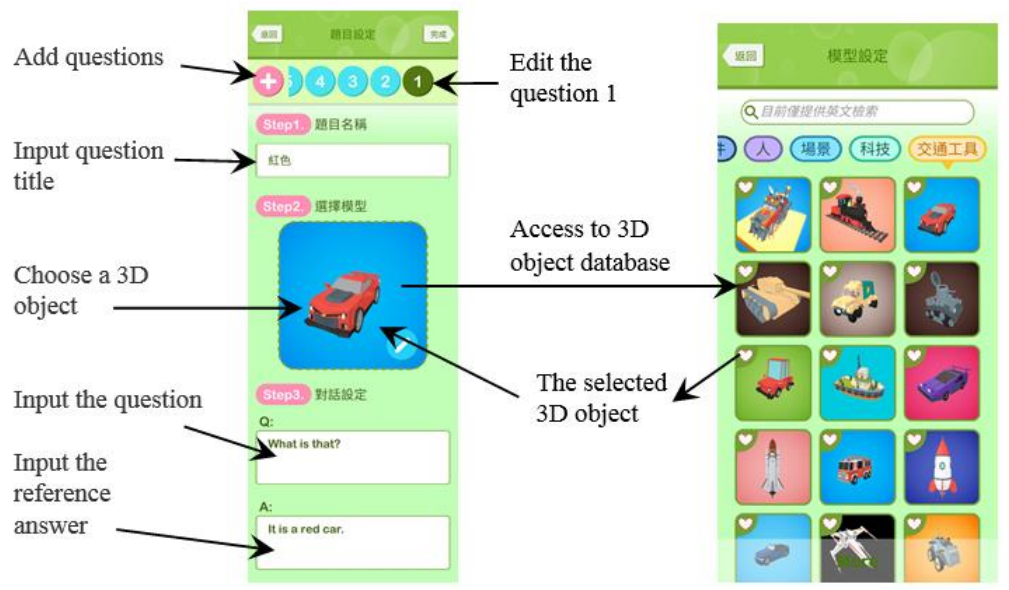

Figure 4. Screenshot of material creation and 3D objects database

\section{Layout design of AR-based mobile English courses developed by using STEMUP}

When students log in and select the desired AR-based English course on their smartphone, the course description on the main page of the course details what they will be learning. This design corresponds to Mayer's (2005) signalling principle in that people learn better when the organisation of the essential material is highlighted. During the learning process, when students use the cameras of their smartphones to point at the target number image on the theme poster and the number image is recognised, its corresponding AR object immediately appears in the middle of the smartphone screen and its corresponding English Q\&A dialogue is simultaneously presented at the bottom of the screen. For example, a Q\&A dialogue with two sentences corresponding to asking and answering about the colour of the motorcycle is shown above in Figure 1. An AR object of a grey motorcycle is simultaneously displayed above its corresponding recognised number image on the student's smartphone. The corresponding words and pictures are simultaneously presented nearby, on the screen, which meets Mayer's (2005) multimedia, spatial contiguity and temporal contiguity principles. This combination of corresponding words and pictures is helpful for EFL learners for increasing vocabulary and improving comprehension and retention (Baralaei \& Najmabadi, 2015; Hashemifardnia et al., 2018).

When students further touch the "horn" icon on the right side of the first English sentence in the dialogue zone, the question sentence is played with audio support from the online service of the Google text-tospeech application. Providing AR graphics and their corresponding narration meets Mayer's (2005) modality principle. In addition, the use of subtitles with English audio support is similar to subtitled video, which effectively enhances the performance of EFL learners in vocabulary, listening and speaking and also promotes their comprehension (Chang et al., 2011; Kanellopoulou, 2019; Saed et al., 2016; Tajgozari, 2019).

When the learner keeps pressing the blue "microphone" icon below the AR object (Figure 1), STEMUP will turn on the speech recording function to record as they say the second sentence in the Q\&A dialogue. When a student releases the "click-on-the-microphone" icon, STEMUP turns off the recording function and automatically turns on Google's speech recognition function to recognise what the student has just spoken and rapidly displays the corresponding script at the bottom of the smartphone screen for the learner's reference. If the recognised script matches the second sentence of the dialogue, a green picture with lovely smile appears in the middle of the screen; if not, a pink picture with sad expression appears. If students cannot correctly or fluently speak the answer sentence, they can touch the "horn" icon to repeatedly listen to the pronunciation of the sentence for correcting or modifying their pronunciation. Prompt written feedback of what students speak is helpful for students to understand their weakness or progress. The correction process enables students to repeatedly practise their English pronunciation and listening and speaking skills. Finally, if students successfully complete all the required Q\&A dialogues of the assigned theme, they receive virtual gold coins and they can return to the main page to start another theme course. All the learning process is done based on the learner's needs and pace, which meets Mayer's (2005) segmenting principle. 


\section{Purpose of the study}

This article reports the implementation of STEMUP into an elective course, Design and Practice of Mobile Learning, provided to EFL students with low computational knowledge or familiarity, in an applied foreign languages department of a technology university in Taiwan in the second semester of the 2019 school year. The aims of this study were, first, to investigate EFL students' perceptions towards the development of ARbased mobile courses on their own by using STEMUP; and second, to explore the perceptions of EFL students of learning English listening and speaking skills in two situation themes (Airport and Bank) with AR-based mobile courses developed by using STEMUP.

\section{Methods}

To examine whether or not STEMUP can be easily used for developing AR-based mobile English courses by EFL users, who generally lack advanced computer knowledge or ability of programming, this study was conducted on a quasi-experimental basis within an existing course. A questionnaire in Chinese with 22 questions was used, consisting of three parts, corresponding to students' brief demographic information and the two tasks assigned in this study:

- two questions regarding students' gender and their experience of using apps for learning English

- questions (Q) 1 to 7 related to their perceptions towards the usage of STEMUP for developing AR-based English courses

- Q8 to Q20 related to their satisfaction with learning the AR-based mobile English courses.

In addition, an open-ended question was provided to enable students to freely express their opinions or comments. The questionnaire was excerpted from previous studies (Tsai, 2015; Wang, 2019) and reviewed by three experienced EFL professors who specialise in the field of CALL to ensure the content validity of the survey. The questionnaire used a 5-point Likert scale: strongly agree/very satisfied (5), agree/satisfied (4), neutral (3), disagree/unsatisfied (2), and strongly disagree/very unsatisfied (1). Points were assigned to question options. All the students' answers were analysed by using IBM SPSS version 20.

\section{Sample}

Based on convenience sampling, the study was conducted with 50 English major junior students in an elective course, Design and Practice of Mobile Learning, from the Department of Applied Foreign Languages at the National Kaohsiung University of Science and Technology in Southern Taiwan. Student English proficiency was determined by an online TOEIC-like test with a total score of 990. The TOEIClike mean of the students were 674, between the levels of B1 (equivalent to TOEIC 550) and B2 (equivalent to TOEIC 785) based on the model of the Common European Framework of Reference for Languages ensured by the Educational Testing Service (2019). They had never learned English with AR-based courses, but most of them had experience of using apps for learning English. Before conducting the study, the approval of the Human Subjects Ethics Committee at National Cheng Kung University was obtained.

The study was conducted in the multimedia laboratory. The students were asked to complete the assigned tasks on their computers. Two tasks were designed for this study. The study process, as shown in Figure 5, was conducted for 100 minutes per week for 4 weeks: 3 weeks for Task 1 on the use of STEMUP for developing AR-based mobile English courses consisting of 8 sets of Q\&A dialogue and 1 week for Task 2 on learning with AR-based mobile English courses on STEMUP. 


\section{Task 1: Use of STEMUP for developing AR-based mobile courses}

1. EFL students downloaded the STEMUP app to their mobile phones.

2. EFL students learned how to use STEMUP.

3. EFL students worked in pairs to produce an AR-based mobile learning course by using STEMUP for fifth- and sixth-grade elementary school students. Each course included 8 sets of Q\&A dialogue at least.

4. EFL students produced an AR-based course by successively completing the following work items: deciding course title, drafting course description, collecting data, editing scripts of each dialogue, keying in content of each dialogue set on STEMUP with their smartphone, choosing corresponding 3D object for each dialogue set and uploading the final version of the AR-based course to STEMUP.

\section{$\Downarrow$}

\section{Task 2: Learning with AR-based mobile courses developed by using STEMUP}

1. EFL students logged in STEMUP and interacted with two AR-based mobile English courses on the workplace themes of Airport and Bank for 40 minutes.

2. EFL students were given a paper of theme poster on which 10 number images have been appropriately placed. Each of number image corresponded to a set of Q\&A dialogue. The learning content of each dialogue set was shown on the screen of the students' mobile phones for practice when the recognition of the number image was achieved.

\section{Questionnaire survey \& data analysis}

1. EFL students had to anonymously complete a 10-minute questionnaire with 22 questions and an open-ended question.

2. All the students' questions were collected and analysed by using IBM SPSS version 20.

Figure 5. Study procedure

During Task 1, the students had to work in pairs to develop an AR-based English course for fifth- and sixthgrade students in elementary school by successively completing the following work items: deciding on course title, drafting course description, collecting data, editing scripts of each dialogue, keying in content of each dialogue set on STEMUP with their smartphone, choosing corresponding 3D object for each dialogue set and uploading the final version of the course to STEMUP. During Task 2, they were required to individually interact with the dialogues of two AR-based English courses on the workplace themes of Airport and Bank for 40 minutes. The teacher served as a facilitator of the students' editing and production process, encouraging them to complete the assigned tasks on their own. After finishing the two tasks, the students had to anonymously complete the questionnaire.

\section{Data analysis}

The SPSS reliability analysis showed that the Cronbach's $\alpha$ value of the questionnaires was 0.865 , higher than an acceptable level of 0.7 , indicating that the items of the questionnaire had relatively high internal consistency. Descriptive analyses were mostly conducted in this study. In addition, an independent sample $t$ test was used in order to determine possible group differences in students' gender and their experience of using apps for learning English.

\section{Results}

According to the first part of the questionnaire, the participants consisted of 42 female students and 8 male students. In addition, 44 students had experience of using apps for learning English. The difference in number between the female and male students in the gender group as well as between the students with and without experience of using apps was great. The students' perceptions towards the use of AR-supported STEMUP app for developing AR-based mobile English courses and learning AR-based English courses developed by using STEMUP are shown in Tables 1 and 2. 


\section{Perceptions about the use of AR-supported STEMUP app for developing AR-based mobile English courses}

The second part of the questionnaire consisted of 7 questions regarding the students' perceptions about the use of AR-supported STEMUP for developing AR-based mobile English courses. The results are shown in Table 1. Some important issues are as follows:

- The overall mean was 4.03 , and there were 4 out of 7 questions with a mean higher than 4 .

- The highest mean was for Q1 $(M=4.40)$ related to the ease of learning how to use STEMUP.

- The second highest mean was for Q6 $(M=4.22)$ concerning the recognition of number images.

- High means were for Q4 $(M=4.06)$ and Q5 $(M=4.14)$ regarding the English speech speed and the interface design provided by STEMUP.

- The mean of students' responses to the clarity (Q2) and correctness (Q3) of English speech provided by STEMUP were 3.92 and 3.73 respectively.

- $\quad$ The mean regarding the animation presentation of AR objects (Q7) was 3.71.

Table 1

Using STEMUP for developing AR-based mobile English courses

\begin{tabular}{llll}
\hline Questions & Mean & SD \\
\hline Q1 & I can quickly learn how to use STEMUP for developing mobile English courses. & 4.40 & .491 \\
Q2 & English speech provided by STEMUP is clear. & 3.92 & .754 \\
Q3 & English speech provided by STEMUP is correct. & 3.73 & .782 \\
Q4 & English speech speed provided by STEMUP is appropriate. & 4.06 & .773 \\
Q5 & The interface of STEMUP is simple to operate. & 4.14 & .536 \\
Q6 & Number images are easy to be recognised. & 4.22 & .687 \\
Q7 & The presentation of AR objects is vivid in action. & 3.71 & .981 \\
\hline \multicolumn{2}{l}{ Overall mean } & 4.03 & \\
\hline
\end{tabular}

\section{Student perceptions of learning AR-based English courses developed by using STEMUP}

The third part of the questionnaire with 13 questions was about student perceptions towards learning with two AR-based mobile English courses developed by using STEMUP on two themes of workplace: Airport and Bank. The results are shown in Table 2. Some important issues are highlighted as follows:

- The overall mean of the questionnaire survey was $4.09 ; 11$ out of the 13 questions had a mean higher than or equal to 4 .

- $\quad$ The highest mean $(M=4.34)$ was for Q9 regarding the convenience of learning English with ARbased mobile courses on STEMUP, and the second highest mean $(M=4.26)$ was for Q14 related to students' learning improvement in vocabulary learning.

- The third highest mean $(M=4.18)$ was for Q13 and for Q20, concerning students' learning improvement in vocabulary pronunciation and students' willingness to continue to learn English with AR-based mobile courses on STEMUP respectively.

- Five questions had high a mean between 4.10 and 4.16 , related to students' interest in (Q10, $M=$ 4.10) and motivation for (Q11, $M=4.10)$ learning with AR-based mobile courses on STEMUP, the accuracy of online speech recognition provided by STEMUP (Q12, $M=4.14$ ), students' improvement in the use of English sentence patterns $(\mathrm{Q} 16, M=4.16)$ and the suitability of learning English speaking skills (Q19, $M=4.12)$ with AR-based mobile courses on STEMUP.

- The mean for Q17 was 4.02, regarding students' improvement in English speaking skill from the help of the instant evaluation and feedback provided by the online services of the text-to-speech, audio recording and speech recognition system.

- The mean for Q15 was 4.00, concerning students' improvement in English listening skills.

- Q8 related to students' interest in the integration of AR objects into English learning had a mean of 3.90, and Q18 about the suitability of learning English listening skill with AR-based mobile courses on STEMUP had a mean of 3.73. 
Table 2

Learning with AR-based English courses developed by using STEMUP

\begin{tabular}{|c|c|c|c|}
\hline \multicolumn{2}{|r|}{ Questions } & \multirow{2}{*}{$\frac{\text { Mean }}{3.90}$} & \multirow{2}{*}{$\frac{S D}{.901}$} \\
\hline Q8 & Integrating AR objects into English learning is interesting. & & \\
\hline Q9 & $\begin{array}{l}\text { AR-based mobile courses on STEMUP can make learning English } \\
\text { more convenient. }\end{array}$ & 4.34 & .653 \\
\hline Q10 & $\begin{array}{l}\text { AR-based mobile courses on STEMUP can enhance my interest in } \\
\text { learning English. }\end{array}$ & 4.10 & .614 \\
\hline Q11 & $\begin{array}{l}\text { Integrating AR-based mobile courses on STEMUP into English } \\
\text { teaching can promote learning motivation. }\end{array}$ & 4.10 & .707 \\
\hline Q12 & Online speech recognition provided by STEMUP is accurate. & 4.14 & .661 \\
\hline Q13 & $\begin{array}{l}\text { Learning with AR-based mobile courses on STEMUP helps me } \\
\text { improve English vocabulary pronunciation. }\end{array}$ & 4.18 & .752 \\
\hline Q14 & $\begin{array}{l}\text { Learning with AR-based mobile courses on STEMUP helps me } \\
\text { improve English vocabulary learning. }\end{array}$ & 4.26 & .648 \\
\hline Q15 & $\begin{array}{l}\text { Learning with AR-based mobile courses on STEMUP helps me } \\
\text { improve English listening skills. }\end{array}$ & 4.00 & .682 \\
\hline Q16 & $\begin{array}{l}\text { Learning with AR-based mobile courses on STEMUP helps me } \\
\text { improve in the use of English sentence patterns. }\end{array}$ & 4.16 & .715 \\
\hline Q17 & $\begin{array}{l}\text { Instant evaluation and feedback from applications of online recording, } \\
\text { text-to-speech and speech recognition provided by STEMUP helps } \\
\text { me improve English speaking skills. }\end{array}$ & 4.02 & .924 \\
\hline Q18 & $\begin{array}{l}\text { AR-based mobile courses on STEMUP are suitable for learning } \\
\text { English listening skills. }\end{array}$ & 3.73 & .668 \\
\hline Q19 & $\begin{array}{l}\text { AR-based mobile courses on STEMUP are suitable for learning } \\
\text { English speaking skills. }\end{array}$ & 4.12 & .662 \\
\hline Q20 & $\begin{array}{l}\text { Learning with AR-based mobile courses on STEMUP enhances my } \\
\text { interest in continuing to use it for English learning. }\end{array}$ & 4.18 & .605 \\
\hline Overa & nean & 4.09 & \\
\hline
\end{tabular}

\section{Questionnaire results keyed to students' gender and experience}

Table 3 indicates the students' responses to the questionnaire based on their gender and experience of using apps for learning English. In terms of gender, the male students $(n=42)$ had a higher overall mean than the female students $(n=8)$ and a higher mean in 15 out of 20 questions. An independent sample $t$ test revealed that the male students had a significantly higher mean than the female students only in Q17 (improved speaking skill from the instant evaluation and feedback provided by STEMUP). In addition, the students with experience of using apps for learning English had a higher overall mean than those without experience, with a higher mean in 13 questions. An independent sample $t$ test revealed no significant difference between students experience of using apps for learning English $(n=44)$ and those $(n=6)$ without that experience, as shown in Table 3. Given the great difference in student numbers in the groups in terms of gender and in experience of using apps for learning English, these results may not be generalised, and more research is still needed. 
Table 3

Students' gender and experience of learning English with apps

\begin{tabular}{lcccccccc}
\hline Questions & \multicolumn{4}{c}{ Gemale $(n=42)$} & \multicolumn{5}{c}{ Male $(n=8)$} & \multicolumn{3}{c}{ With apps $(n=44)$} & Without apps $(n=6)$ \\
\cline { 2 - 8 } & Mean & $S D$ & Mean & $S D$ & Mean & $S D$ & Mean & $S D$ \\
\hline Q1 & 4.38 & .492 & 4.50 & .535 & 4.41 & .497 & 4.33 & .516 \\
Q2 & 3.90 & .726 & 4.00 & .926 & 3.89 & .754 & 4.17 & .753 \\
Q3 & 3.74 & .767 & 3.63 & .916 & 3.75 & .781 & 3.50 & .837 \\
Q4 & 4.00 & .765 & 4.38 & .744 & 4.02 & .792 & 4.33 & .516 \\
Q5 & 4.14 & .566 & 4.13 & .354 & 4.18 & .540 & 3.83 & .408 \\
Q6 & 4.19 & .707 & 4.38 & .518 & 4.25 & .686 & 4.00 & .632 \\
Q7 & 3.90 & .932 & 3.75 & .886 & 3.89 & .970 & 3.83 & .408 \\
Q8 & 3.67 & 1.028 & 3.75 & 1.282 & 3.68 & 1.073 & 3.67 & 1.033 \\
Q9 & 4.31 & .643 & 4.50 & .535 & 4.34 & .645 & 4.33 & .516 \\
Q10 & 4.07 & .640 & 4.25 & .707 & 4.09 & .640 & 4.17 & .753 \\
Q11 & 4.05 & .623 & 4.38 & .518 & 4.09 & .640 & 4.17 & .408 \\
Q12 & 4.12 & .705 & 4.25 & .707 & 4.11 & .722 & 4.33 & .516 \\
Q13 & 4.14 & .647 & 4.38 & .744 & 4.16 & .645 & 4.33 & .816 \\
Q14 & 4.19 & .773 & 4.63 & .518 & 4.27 & .758 & 4.17 & .753 \\
Q15 & 3.95 & .623 & 4.25 & .707 & 4.02 & .628 & 3.83 & .753 \\
Q16 & 4.17 & .660 & 4.13 & .835 & 4.20 & .668 & 3.83 & .753 \\
Q17 & 3.93 & .712 & $4.50 *$ & .535 & 4.02 & .731 & 4.00 & .632 \\
Q18 & 3.69 & .897 & 3.50 & 1.069 & 3.75 & .918 & 3.00 & .632 \\
Q19 & 4.07 & .677 & 4.38 & .518 & 4.16 & .645 & 3.83 & .753 \\
Q20 & 4.14 & .608 & 4.38 & .518 & 4.16 & .608 & 4.33 & .516 \\
\hline Overall mean & 4.02 & .721 & 4.20 & .703 & 4.07 & .717 & 3.98 & .652 \\
\hline
\end{tabular}

${ }^{*} p<.05$, significant difference

\section{Students' responses to the open-ended question}

Some students freely expressed their opinions or suggestions on the open-ended question, mainly focusing on four issues: Five students identified that learning with AR-based mobile English courses on STEMUP was easy, simple, interesting and motivational. Five students thought that there were not enough 3D objects for an AR presentation corresponding to the dialogue sets that they developed. Four students mentioned that their dialogue speech was sometimes not well recognised. In addition, four students mentioned a problem with power consumption during the learning process.

\section{Discussion}

According to the students' response to the second part of the questionnaire survey (Table 1), the results indicate that STEMUP is seen as a simple and easy application for junior English majors with little computer knowledge or programming ability. They felt able to easily develop AR-based mobile English courses for fifth- and sixth-grade students in elementary school. For example, the highest mean for Q1 ( $M$ $=4.40)$ and a high mean for Q5 $(M=4.14)$ confirmed that students were able to quickly learn how to use STEMUP and its simple interface for developing mobile AR-based English courses. They also stated that the recognition of number images was easy $(\mathrm{Q} 6, M=4.22)$, the online service of Google text-to-speech and speech recognition connected with STEMUP provided clear audio quality $(\mathrm{Q} 2, M=3.92)$ and correct audio quality $(\mathrm{Q} 3, M=3.73)$ and that its speech speed was appropriate $(\mathrm{Q} 4, M=4.06)$. In addition, the students stated that the presentation of AR objects was vivid in action (Q7, $M=3.71)$. These results suggest that the simple interface and quick interaction mechanisms provided by STEMUP enable EFL students to effectively create a friendly and vivid AR-based environment for learning English. The above results respond to the first research question of this study.

The students' responses to the third part of the questionnaire indicated that learning with AR-based mobile English courses on STEMUP was convenient (Q9, $M=4.34)$, probably resulting from its mobile learning feature without limitation of time and space, and that it would enhance their interest in learning English (Q10, $M=4.10)$. They also stated that integrating these AR-based mobile courses into English teaching 
can promote their learning motivation (Q11, $M=4.10)$. These positive attitudes resulted in their being willing to continue to learn English with AR-based mobile English courses on STEMUP (Q20, $M=4.18$ ). Since it was the first time for them to experience such AR-based mobile English courses, they were intrigued by the application of this new AR technology and would be interested and motivated in interacting with AR-based mobile English courses on STEMUP. These results echoed that the convenience and ease of use of the AR-based mobile English courses on STEMUP are helpful for facilitating usefulness and attitude towards using them; and therefore, continued intention to use is enhanced (Chang et al., 2012). These results also suggest that STEMUP is a powerful tool for creating an interactive and motivational learning environment for EFL students to practise English skills.

By connecting to the online services of Google's text-to-speech and speech recognition, STEMUP provided clear and accurate audio quality $(\mathrm{Q} 2, M=3.92 ; \mathrm{Q} 3, \mathrm{M}=3.73 ; \mathrm{Q} 12, M=4.14)$ and its speech speed $(\mathrm{Q} 4, M$ = 4.06) was appropriate. Most EFL students felt their improvement in vocabulary pronunciation (Q13, $M$ = 4.18), listening $(\mathrm{Q} 15, M=4.00)$ and speaking skills $(\mathrm{Q} 16, M=4.16)$ so that they stated that AR-based mobile English courses on STEMUP were suitable for learning listening $(\mathrm{Q} 18, M=3.73)$ and speaking skills $(\mathrm{Q} 19, M=4.12)$. The vivid in action $(\mathrm{Q} 7, M=3.71)$ and interesting $(\mathrm{Q} 8, M=3.90)$ presentation of AR objects combined with the quick recognition of the number images (Q6, $M=4.22)$ integrated into ARbased mobile English courses into teaching would, they reported, enhance learning motivation $(\mathrm{Q} 11, M=$ 4.10). Learning motivation is an important affective variable for facilitating students' willingness to communicate in a second language (Lee \& Drajati, 2019). In order to practise English listening and speaking skills, the sentences of each Q\&A dialogue shown on the smartphone screen can be played with audio support from the online service of Google text-to-speech application. These visual and auditory technologies play an important role for creating an effective and interactive language learning environment in which students' learning attention can be drawn and their motivation can be enhanced. The students' positive perceptions about learning with AR-based mobile English courses on STEMUP responded to the second research question of the study. In addition, STEMUP offers the online service of course management and learning portfolio for tracking in order to help learners and teachers understand the learning progress of individual students in certain assigned courses.

According to the students' responses to the second part of the questionnaire regarding learning with ARbased English courses developed by using STEMUP, we present more discussion from the perspective of second language acquisition. A high mean for the improvement in the target English skills, including vocabulary pronunciation $(\mathrm{Q} 13, M=4.3)$, vocabulary learning $(\mathrm{Q} 14, M=4.26)$, listening $(\mathrm{Q} 15, M=4.00)$ and speaking skills $(\mathrm{Q} 16, M=4.16)$, revealed that linguistic features emphasised in the AR-based mobile English courses on STEMUP were necessary and helpful in enhancing students' English skill. This outcome compiles with Chapelle's (1998) first suggestion to make key linguistic characteristics salient by highlighting them in written and aural input, in AR objects, or through transcription of dialogues containing linguistic elements in this study.

A high mean $(\mathrm{Q} 17, M=4.02)$ for the instant evaluation and feedback on speaking skill indicates that during the learning process with AR-based mobile English courses on STEMUP, EFL students were able to receive linguistic input through written language or scripts from each dialogue and Google speech recognition service or aural support from Google text-to-speech service to modify their input through repetition, nonverbal cues or dialogue scripts shown on the smartphone screen. These measures meet Chapelle's (1998) second suggestion to offer modifications of linguistic input. In addition, STEMUP provided EFL students with opportunities for repeated speaking practice. This spoken comprehensible output in English can stretch their oral competence, corresponding to Chapelle's third suggestion in providing opportunities for comprehensible output.

The evaluation with instant feedback provided by STEMUP enables EFL students to analyse, recheck, reflect, identify and even correct their errors in pronunciation and speaking skills. This design corresponds to Chapelle's (1998) fourth and fifth suggestions in providing opportunities for learners to recognise their errors and to correct their linguistic output. In addition, these activities regarding linguistic modification increase the learning interaction in English between students and the AR-based mobile course developed by using STEMUP and provides EFL students with more opportunities to practise vocabulary learning and pronunciation as well as listening and speaking skills of each Q\&A dialogue. This outcome meets Chapelle's sixth suggestion in supporting modified interaction between the learner and the computer. The learning process of each Q\&A dialogue could be considered as a task in which EFL students have to 
complete the required linguistic activities provided in all the Q\&A dialogues of each theme course. A virtual gold coin is awarded by STEMUP when the task is completed. Thus, EFL students act as participants in these English tasks during the learning process. This design complies with Chapelle's seventh suggestion in that students can participate in tasks of a second language.

According to the results of this study, the EFL students developed positive perceptions about the use of STEMUP to produce AR-based mobile English courses, focused on vocabulary acquisition, listening and speaking skills. These results supported the design concept of STEMUP as a simple and easy application for the development of AR-based mobile English courses, especially for those who generally have less computer knowledge or lack programming skills, like the EFL students in this study. The AR-based mobile courses developed by using STEMUP are in accordance with a number of Mayer's (2005) principles of multimedia learning, with the potential of lowering learners' cognitive load and enhancing effective learning. In addition, from the perspective of language learning, the AR-based mobile English courses on STEMUP correspond to seven design features and evaluation criteria suggested by Chapelle (1998) for the development of multimedia CALL. After learning with two AR-based mobile English courses on the theme of Airport and Bank developed by using STEMUP, the EFL students felt improvement in learning vocabulary, listening and speaking skills and were willing to keep learning with AR-based mobile English courses on STEMUP. Furthermore, they stated that the integration of these AR-based mobile English courses into teaching would be interesting and motivational. In general, increasing the learning interest and motivation of students is a major advantage while using AR in education (Küçük et al., 2014; Solak \& Cakir, 2015; S. Zhang, 2018), which usually leads to better improvement. The positive response here is gratifying.

\section{Implications}

These EFL students, who lacked computer knowledge or programming skills, showed positive perceptions towards the convenience and simplicity of using STEMUP to easily develop AR-based mobile English courses. This result indicated that they were able to successfully produce AR-based mobile English courses on their own. It is encouraging for English teachers to have a tool with which to break through the dilemma of a lack of technical skills or support. They can be more confident and comfortable in developing ARbased mobile English courses by using STEMUP according to their teaching needs. In addition, learning with the two AR-based mobile English courses developed with STEMUP enhanced students' interest and stimulated their motivation, which led to a great satisfaction. This result suggests that EFL teachers can make use of the features of AR-based mobile English courses on STEMUP to design diverse, rich and flexible curricula for English learning within and outside the classroom.

This study is in its initial stages, beginning first with EFL students majoring in English. The EFL students' positive perceptions in this study suggest that it is necessary to encourage English teachers to know more about AR and even work with programmers and experts in the field of AR technology, which can start a deeper investigation and a better understanding about the potential benefits and possible challenges brought by AR application in English learning and teaching. Of course, EFL teachers' willingness, beliefs and contributions are needed to further promote such a potential and favourable AR-based MALL approach.

With STEMUP, developing friendly, interesting, interactive and effective AR-based English courses is no longer impossible for EFL teachers. They can pay more attention to AR-based curriculum and content design. For example, a range of diverse and adaptive learning activities could be planned, developed and then applied with students from different educational backgrounds; furthermore, game-based instructional elements could also be considered to strengthen the application of AR features. Using these features could improve teaching quality and increase learning effectiveness. More research should be conducted to investigate the possible influence or impact of the above variables on the development of AR-based mobile English courses and their implementation into learning.

\section{Conclusion}

The present study aimed at investigating student perceptions towards the usage of the AR-supported STEMUP to develop AR-based mobile English courses and the effectiveness of learning English in two situation themes (Airport and Bank) with AR-based mobile courses developed by using STEMUP. The EFL 
students (who have with low computer ability) were able to easily develop AR-based mobile English courses for fifth- and sixth-grade elementary school students. The layout design of the AR-based mobile English courses developed by using STEMUP complied with several of Mayer's (1998) principles of multimedia learning. In addition, the language focus of learning with the AR-based mobile English courses on STEMUP drew on Chapelle's (1998) seven suggested criteria for the development of multimedia CALL. The EFL students were exposed to a variety of learning activities in the target Q\&A dialogues and engaged in interacting with the dialogue content for practising vocabulary, listening and speaking skills at their own pace on their individual smartphones, and at the same time, obtain instant feedback through the online evaluation system. The results suggested that learning with the AR-based mobile English courses developed on STEMUP enables learners to acquire and develop the above English skills.

This exploratory study is to investigate the convenience of producing AR-based mobile English courses by using STEMUP and EFL students' preliminary perceptions towards learning with two English courses on STEMUP. Some limitations of this study are highlighted as follows:

- The limited sample $(N=50)$ of the EFL students with a great difference in numbers in the groups in terms of gender and in experience of using apps for learning English may result in the impossibility of generalising the results of this study. Thus, the results analysed by using the independent sample $t$ test in this study should be interpreted with caution.

- The participants were selected through convenience sampling with an already-existing course. Accordingly, more classroom-oriented research should be conducted with students from other educational stages or with other courses.

- Since the learning time and subjects were limited in this study, research with a longer period of learning with AR-based mobile English courses on STEMUP could be conducted.

In Taiwan, the Ministry of Education (2020) has proposed key competences for students of higher technical and vocational education, consisting of interdisciplinary learning ability and international mobility. Accordingly, students are encouraged to equip themselves with both English and technology skills. Integrating AR technologies into English instruction could be a feasible approach. This study successfully set up a preliminary and interdisciplinary curriculum to integrate STEMUP into instruction. The EFL students not only learnt how to develop AR-based mobile English courses by using STEMUP but also improved their English skills, mainly in vocabulary, listening and speaking, by learning with AR-based mobile English courses on STEMUP. These features suggest that developing AR-based mobile English courses on STEMUP and integrating them into learning within or outside classrooms can be a most useful potential application in English education.

In the future, the focus of this study will be extended to promote this AR-supported STEMUP application in educational settings, especially in remote schools that lack English learning resources and teachers. With the user-friendly features provided by STEMUP, teachers can easily develop and implement AR-based mobile English courses aligned with their curriculum design. By doing so, students can be provided with more learning resources and opportunities, and meanwhile teachers can investigate students' learning effectiveness and their perceptions to improve teaching quality.

\section{Acknowledgements}

This work has been funded by Institute of Information Industry, Taiwan, under Contract of Innovation Project: Number 108-1865.

\section{References}

Bacca, J., Baldiris, S., Fabregat, R., \& Kinshuk. (2019). Framework for designing motivational augmented reality applications in vocational education and training. Australasian Journal of Educational Technology, 35(3), 102-117. https://doi.org/10.14742/ajet.4182

Baralaei, S, Najmabadi, A. (2015). The effect of using images on vocabulary learning on EFL learners. International Journal of Research on English Language Teaching Studies, 3(2), 17-19. https://www.academia.edu/31581605/The Effect_of Using_Images on Vocabulary Learning On E $\underline{\text { FL Learners }}$ 
Cabero, J., \& Roig, R. (2019). The motivation of technological scenarios in augmented reality (AR): Results of different experiments. Applied Science, 9(14), Article 2907.

https://doi.org/10.3390/app9142907

Celik, C., Guven, G., \& Kozcu, N. (2020). Integration of mobile augmented reality (MAR) applications into biology laboratory: Anatomic structure of the heart. Research in Learning Technology. 28, 1-11. https://doi.org/10.25304/rlt.v28.2355

Chang, C.-C., Lei, H., \& Tseng, J.-S. (2011). Media presentation mode, English listening comprehension and cognitive load in ubiquitous learning environments: Modality effect or redundancy effect? Australasian Journal of Educational Technology, 27(4), 633-654. https://doi.org/10.14742/ajet.942

Chapelle, C. A. (1998). Multimedia CALL: Lessons to be learned from research on instructed SLA. Language Learning \& Technology, 2(1), 22-34. https://www.lltjournal.org/item/2260

Cheon, H. (2003). The viability of computer mediated communication in the Korean secondary EFL classroom. Asian EFL Journal, 5(1), 1-61. https://www.asian-efl-journal.com/main-journals/theviability-of-computer-mediated-communication-in-the-korean-secondary-efl-classroom/

de Almeida Mello, G. N., \& Cabero Almenara, J. (2020). Aid-augmented reality for reinforced concrete class: students' perception. Alteridad, 15(1), 12-23. https://doi.org/10.17163/alt.v15n1.2020.01

Delgado, J. M. D., Oyedele, L., Demian, P., \& Beach, T. (2020). A research agenda for augmented and virtual reality in architecture, engineering and construction. Advanced Engineering Informatics, 45. https://doi.org/10.1016/j.aei.2020.101122

Educational Testing Service. (2019). TOEIC $®$ score vs CEFR. https://yourenglishtest.com/article/index/art/54

Fidan, M., \& Tuncel, M. (2019). Integrating augmented reality into problem based learning: The effects on learning achievement and attitude in physics education. Computers \& Education, 142, Article 103635. https://doi.org/10.1016/j.compedu.2019.103635

Habig, S. (2019). Who can benefit from augmented reality in chemistry? Sex differences in solving stereochemistry problems using augmented reality. British Journal of Educational Technology, 51(3), 629-644. https://doi.org/10.1111/bjet.12891

Hao, H. C., \& Lee, L. C. (2019). The development and evaluation of an educational game integrating augmented reality, ARCS model, and types of games for English experiment learning: An analysis of learning. Interactive Learning Environment. https://doi.org/10.1080/10494820.2019.1619590

Hashemifardnia, A., Namaziandost, E., \& Esfahani F. R. (2018). The effect of teaching picture-books on elementary EFL learners' vocabulary learning. Journal of English Language Teaching and Linguistics, 3(3), 247-258. http://jeltl.org/index.php/jeltl/article/view/151/pdf

Hsu, T. C. (2017). Learning English with augmented reality: Do learning styles matter? Computers \& Education, 106, 137-149. https://doi.org/10.1016/j.compedu.2016.12.007

Huang, Y. M., \& Chiu, P. S. (2014). The effectiveness of a meaningful learning-based evaluation model for context-aware mobile learning. British Journal of Educational Technology, 46(2), 437-447. https://doi.org/10.1111/bjet.12147

Hwang, W.-Y., Huang, Y.-M., Shadiev, R., Wu, S.-Y., \& Chen, S.-L. (2014). Effects of using mobile devices on English listening diversity and speaking for EFL elementary students. Australasian Journal of Educational Technology, 30(5), 503-516. https://doi.org/10.14742/ajet.237

Hwang, W. Y., Shih, T. K., Ma, Z. H., Shadiev, R., \& Chen, S. Y. (2016). Evaluating listening and speaking skills in a mobile game-based learning environment with situational contexts. Computer Assisted Language Learning, 29(4), 639-657. https://doi.org/10.1080/09588221.2015.1016438

Ibrahim, E. I. M. (2019). Mobile learning for English language learning: Benefits and challenges. European Journal of Open Education and E-learning Studies, 4(1), 44-59. https://oapub.org/edu/index.php/ejoe/article/view/2290/4929

Ibrahim, A., Huynh, B., Downey, J., Höllerer, T., Chun, D., \& O'Donovan, J. (2017). ARbis Pictus: A study of language learning with augmented reality. IEEE Transactions on Visualization and Computer Graphics, 2867-2874. https://arxiv.org/abs/1711.11243

Kanellopoulou, C. (2019). Film subtitles as a successful vocabulary learning tool. Open Journal of Modern Linguistics, 9, 145-152. https://doi.org/10.4236/ojml.2019.92014

Küçük, S., Yılmaz, R. M., \& Göktaş, Y. (2014). Augmented reality for learning English: Achievement, attitude and cognitive load levels of students. Education and Science, 39(176), 393-404. http://egitimvebilim.ted.org.tr/index.php/EB/article/view/3595/884

Lee, J. S., \& Drajati, N. A. (2019). Affective variables and informal digital learning of English: Keys to willingness to communicate in a second language, Australasian Journal of Educational Technology, 35(5), 168-182. https://doi.org/10.14742/ajet.5177 
Liu, P.-H. E., \& Tsai, M.-K. (2013). Using augmented-reality-based mobile learning material in EFL English composition: An exploratory case study. British Journal of Educational Technology, 44(1), E1-E4. https://doi.org/10.1111/j.1467-8535.2012.01302.x

Liu, T.-Y. (2009). A context-aware ubiquitous learning environment for language listening and speaking. Journal of Computer Assisted Learning, 25, 515-527. https://doi.org/10.1111/j.1365-2729.2009.00329.x

Liu, Y., Holden, D., \& Zheng, D. (2016). Analyzing students' language learning experience in an augmented reality mobile game: An exploration of an emergent learning environment. Procedia: Social and Behavioral Sciences, 228, 369-374. https://doi.org/10.1016/j.sbspro.2016.07.055

Liu, Y.-C., \& Hsieh, H.-S. (2018). Study on the effect of augmented reality use time on English learning. In Proceedings of the International Conference on Education, Teaching \& Learning (pp. 1-7). http://globalbizresearch.org/Swiss_Conference_2018 July1/docs/doc/4.\%20Education/ZE899.pdf

Lu, H. W., Lee, J. Y., \& Lin, M. H. (2019). Effects of authentic English-language videos on EFL students' speaking anxiety. International Journal of Information and Education Technology, 9(6), 423-428. http://www.ijiet.org/vol9/1239-JR326.pdf

Mayer, R. E. (2005). The Cambridge Handbook of multimedia learning. Cambridge University Press.

Ministry of Education. (2020). 技術及職業教育政策綱領 [Policy principles for technical and vocational education]. https://ws.moe.edu.tw/001/Upload/3/relfile/6315/52872/8e95fa4b-84a9-4656-938b1a8de94cf5e2.pdf

Moreno, A. J., Alonso, S., Ramos Navas-Parejo, M., Campos-Soto, M. N., \& Gómez García, G. (2020). Augmented reality as a resource for improving learning in the physical education classroom. International Journal of Environmental Research and Public Health, 17(10), Article 3637. https://doi.org/10.3390/ijerph17103637

Nami, F. (2020). Educational smartphone apps for language learning in higher education: Students' choices and perceptions. Australasian Journal of Educational Technology, 36(4), 82-95. https://doi.org/10.14742/ajet.5350

Perry, B. (2015). Gamifying French language learning: A case study examining a quest-based, augmented reality mobile learning-tool. Procedia: Social and Behavioral Sciences, 174, 2308-2315. https://doi.org/10.1016/j.sbspro.2015.01.892

Radosavljevic, S., Radosavljevic, V., \& Grgurovic, B. (2018). The potential of implementing augmented reality into vocational higher education through mobile learning. Interactive Learning Environments, 28(4), 404-418. https://doi.org/10.1080/10494820.2018.1528286

Saed, A., Yazdani, A., \& Askary, M. (2016). Film subtitles and listening comprehension ability of intermediate EFL learners. International Journal of Applied Linguistics and Translation, 2(3), 29-32. http://article.sciencepublishinggroup.com/html/10.11648.j.ijalt.20160203.12.html

Safar, A. H., Al-Jafar, A. A., \& Al-Yousefi, Z. H. (2017). The effectiveness of using augmented reality apps in teaching the English alphabet to kindergarten children: A case study in the State of Kuwait. Eurasia Journal of Mathematics, Science \& Technology Education, 13(2), 417-440. https://doi.org/10.12973/eurasia.2017.00624a

Sahin, D., \& Yilmaz, R. M. (2020). The effect of Augmented Reality Technology on middle school students' achievements and attitudes towards science education. Computers \& Education, 144, 103710. https://doi.org/10.1016/j.compedu.2019.103710

Santos, M. E., Lübke, A., Taketomi, T., Yamamoto, G., Rodrigo, M., Sandor, C., \& Kato, H. (2016). Augmented reality as multimedia: The case for situated vocabulary learning. Research and Practice in Technology Enhanced Learning, 11(4), 1-23. https://doi.org/10.1186/s41039-016-0028-2

Solak, E., \& Cakir, R. (2015). Exploring the effect of materials designed with augmented reality on language learners' vocabulary learning. The Journal of Educators Online, 13(2), 50-72. https://www.thejeo.com/archive/archive/2015 122/solak_articlepdf

Tajgozari, M. (2019). The effect of watching captioned TV series on speaking accuracy of Iranian advanced EFL learners. Global Journal of Foreign Language Teaching, 9(3), 157-166. https://doi.org/10.5296/jsel.v3i1.8301

Tang, K. S., Cheng, D. L., Mi, E., \& Greenberg, P. B. (2020). Augmented reality in medical education: A systematic review. Canadian Medical Education Journal, 11(1), e81-e96. https://doi.org/10.36834/cmej.61705

Tsai, S. C. (2015). Implementing courseware as the primary mode of task-based ESP instruction: A case study of EFL students. Computer Assisted Language Learning, 28(2), 171-186. https://doi.org/10.1080/09588221.2013.818554

Tsou, W. (2005). Improving speaking skills through instruction in oral classroom participation. Foreign 
Language Annals, 38, 46-55. https://doi.org/10.1111/j.1944-9720.2005.tb02452.x

Wang, S. C. (2019). The development and evaluation of a bilingual audio mobile application for hotel industry and personnel in Taiwan [Unpublished master dissertation]. National Kaohsiung University of Science \& Technology.

Yilmaz, R. M., Kucuk, S., \& Goktas, Y. (2017). Are augmented reality picture books magic or real for preschool children aged five to six? British Journal of Educational Technology, 48(3), 824-841. https://doi.org/10.1111/bjet.12452

Zhang, J., Sung, Y.-T., Hou, H.-T., \& Chang, K.-E. (2014). The development and evaluation of an augmented reality-based armillary sphere for astronomical observation instruction. Computers \& Education, 73, 178-188. https://doi.org/10.1016/j.compedu.2014.01.003

Zhang, S. (2018). Augmented reality in foreign language education: A review of empirical studies. Journal of Technology and Chinese Language Teaching, 9(2), 116-133. http://www.tclt.us/journal/2018v9n2/zhangsl.pdf

Corresponding author: Shu-Chiao Tsai, achiao@nkust.edu.tw

Copyright: Articles published in the Australasian Journal of Educational Technology (AJET) are available under Creative Commons Attribution Non-Commercial No Derivatives Licence (CC BY-NC-ND 4.0). Authors retain copyright in their work and grant AJET right of first publication under CC BY-NC-ND 4.0.

Please cite as: Lin, H.-Y., \& Tsai, S.-C. (2021). Student perceptions towards the usage of AR-supported STEMUP application in mobile courses development and its implementation into English learning. Australasian Journal of Educational Technology, 37(3), 88-103. https://doi.org/10.14742/ajet.6125 